\title{
A presença do idoso na publicidade de medicamentos no Brasil
}

\author{
Paula Renata Camargo de Jesus \\ Universidade Presbiteriana Mackenzie
}

\begin{abstract}
Resumo
A longevidade cresce no Brasil e no mundo. Também cresce o consumo de medicamentos. Por isso, cada vez mais, os idosos são o alvo da publicidade de medicamentos no Brasil. Nas campanhas de publicidade, os idosos geralmente aparecem com a família. Este texto, que faz parte de uma pesquisa mais ampla, tem como objetivo verificar os idosos como consumidores brasileiros atuais e sua presença na campanha de medicamentos no Brasil: Benegrip Multi.
\end{abstract}

\section{Palavras-chave:}

Campanha de medicamentos. Idosos. Brasil.

\section{Introdução}

Quando me propus a participar do ALAIC 2018, ponderei sobre a importância de inscrever um trabalho que pudesse contribuir com informações e reflexões na minha área de pesquisa. São vinte anos dedicados à pesquisa e publicações a respeito do Consumidor e da Publicidade de Medicamentos no Brasil. Como o tema proposto pelo ALAIC tem relação com inclusão, achei por bem apresentar um recorte do meu estudo, que contempla a presença do idoso na publicidade de medicamentos. $\mathrm{O}$ presente texto está organizado em três partes: a primeira apresenta o panorama do consumidor idoso no Brasil. A segunda propõe o levantamento de informações da indústria farmacêutica e da publicidade de medicamentos no Brasil. A terceira parte busca verificar a campanha publicitária do medicamento Benegrip Multi, que utiliza o discurso da maturidade, tendo como protagonista a famosa atriz, idosa, Nicette Bruno. O trabalho tem como objetivos: contextualizar o consumo de medicamentos, apresentar dados relevantes a respeito do crescimento da população idosa no Brasil e estabelecer uma relação do idoso com a publicidade de medicamentos. Como leitura de campanha, a proposta é verificar a presença do idoso na publicidade de medicamentos na campanha Benegrip Multi. Por fim, o trabalho busca reflexões e faz contribuições a respeito do tema principal. 


\section{Consumidor idoso no Brasil}

Idoso? Pessoa idosa? Velhice? Terceira idade? Melhor idade? Pessoas longevas? Afinal qual a melhor palavra ou termo para se referir ao consumidor acima dos 60 anos?

Em 1963, a Organização Mundial de Saúde, fez uma divisão das faixas etárias, considerando meia idade: 45 a 59 anos; idosos: 60 a 74 anos ; anciãos: 75 a 90 anos e velhice extrema: 90 anos ou mais (Portal Jus, 2004).

No presente texto será utilizada a palavra 'idoso', uma vez que é a que mais se apresenta em publicações que se referem a pessoas acima de 60 anos.

O estudo se justifica porque no Brasil o crescimento de idosos é consideravelmente grande. Consequentemente o aumento do consumo de medicamentos também.

Segundo o IBGE (Instituto Brasileiro de Geografia e Estatística) a estimativa populacional do Brasil conta com 207 milhões de habitantes. Um índice importante é que em menos de uma década, o Brasil aumentou em 8,5 milhões o número de idosos.

Ou seja, a população acima dos 60 anos de idade deve passar de 14,9 milhões (7,4\% do total), de 2013 , para 58,4 milhões ( $26,7 \%$ do total) até 2060 , devido ao contínuo aumento da expectativa de vida (Portal Conselho Federal de Farmácia, 2016).

De acordo com o Relatório Mundial sobre Envelhecimento e Saúde, divulgado pela OMS (Organização Mundial de Saúde), "uma criança nascida em 2015 no Brasil ou em Mianmar, pode esperar viver 20 anos mais que uma criança nascida há 50 anos". Inclusive no país, o número de pessoas com mais de 60 anos deverá crescer muito mais rápido que a média mundial.

O Estatuto do Idoso (Lei no 10.741 , de $1^{\circ}$ de outubro de 2003) completou 14 anos e é considerado um marco jurídico para a proteção da população idosa brasileira.

A questão do envelhecimento está presente em todas as sociedades e necessita de medidas que assegurem os "direitos do idoso" ou a "proteção à velhice" que estão situados, principalmente, entre os direitos sociais. Constam dos Planos de Ação Internacionais para o Envelhecimento (ONU 1982/2002) objetivos que recomendam às autoridades dos diferentes países adotar medidas de apoio às pessoas idosas, tanto no campo jurídico como na implementação de políticas sociais, devendo ainda seguir as três linhas prioritárias que são: pessoas idosas e desenvolvimento; saúde e bem-estar na velhice e entorno propício e favorável.

Nas décadas anteriores, o idoso era apresentado e representado negativamente, com dependência total e isolamento. Era comum a mídia apresentar o idoso de maneira dramática ou por meio da comicidade.

Infelizmente, por anos o Brasil ignorou a sua população idosa, se apoiando na imagem de um país jovem. Mas o fenômeno do envelhecimento é inevitável. Porém a maneira de encarar a velhice mudou. "Cinquenta anos atrás, ser idoso era completamente diferente de hoje, isso porque não se espera do idoso de hoje uma atitude passiva diante da vida" (Zanchi, Zugno, 2012, p. 359).

Em relação ao consumo, produtos e marcas parecem ainda estarem desprepa- 
rados, assim como estratégias de marketing e publicidade, para com o idoso. Uma pesquisa pelo SPC (Serviço de proteção ao crédito) pela Confederação Nacional de Dirigentes Lojistas (CNDL) relatou que 67\% dos idosos são os únicos decisores sobre as compras que fazem, mas três em cada dez (34\%) afirmam sentir falta de produtos para a terceira idade (Portal M\&M, 2016).

"É um consumidor que nem todo mercado está preparado para tratar. As marcas se preocupam com a geração atual e esquecem uma grande massa de pessoas que detêm o capital e tomam as decisões", avalia Marcos Callegari, diretor de projetos da Escopo Geomarketing, empresa especializada em pesquisa de mercado.

Os meios de comunicação mais consumidos pela terceira idade são TV aberta (80\%), rádio (50\%), TV por assinatura (45\%) e internet (43\%). Ente os conteúdos que interessam este público estão novelas, filmes e saúde (Portal M\&M, 2016).

\section{Publicidade de medicamentos no Brasil}

O consumo irracional de medicamentos do brasileiro só aumenta. $\mathrm{O}$ brasileiro tem o hábito de se automedicar. Talvez por herança cultural, pela forte presença da indústria farmacêutica no início da publicidade brasileira, pelo alto índice de prescrição e, inclusive, escândalos da classe médica em parceria com os laboratórios. É no consumo, na dependência, na fidelidade às marcas, que a indústria farmacêutica investe. Não à toa, existem linhas de medicamentos voltadas para todas as fases da vida: infância, adulto, velhice.

Segundo Nascimento (2005, p. 22), a exploração do valor simbólico do medicamento, socialmente sustentado pela indústria farmacêutica, agências de propaganda e empresas de comunicação, passa a representar um dos mais poderosos instrumentos para a indução e fortalecimento de hábitos voltados para o aumento de seu consumo. "Os medicamentos passam a simbolizar possibilidades imediatas de acesso não apenas à saúde, mas ao bem estar e à própria aceitação social.”

Quando se trata de compra de medicamentos, segundo pesquisa ACNilsen, o brasileiro possui a maior frequência de compra de medicamentos OTC (over-the-counter - vendidos sem prescrição médica) da América Latina. Mais da metade da população do país compra esses produtos ao menos uma vez por mês. Do outro lado, gripes e resfriados têm um alcance ainda maior, 59\% da população, com uma alta frequência nos primeiros anos de vida ( 0 a 5 anos) e destaque na faixa etária com mais de 56 anos, onde complicações tendem a serem maiores.

Se medicamento é produto submetido às lógicas comerciais, fica difícil controlar seu consumo, quem dirá seu autoconsumo.

O risco de consumo de medicamentos inadequados ou o uso irracional de medicamentos, sobretudo os medicamenos vendidos sem prescrição médica em farmácias, é alarmante no público idoso.

"Os idosos geralmente têm problemas de saúde e são incitados pela publicidade a resolvê-los com a automedicação. Importa sublimar o grande número de medicamentos em venda livre e estímulo irresponsável ao seu consumo." (Lopes, 2000, p. 52). 
Profissionais da saúde com foco na terceira idade sabem que determinados medicamentos podem trazer riscos que superam os benefícios, principalmente se consumidos nessa fase da vida. Para servir de alerta, a Sociedade Americana de Geriatria atualizou a lista chamada de "Stopp-Start", cujo objetivo é divulgar os medicamentos que podem ser potencialmente inapropriados para essas pessoas. No Brasil, o Instituto para Práticas Seguras no Uso de Medicamentos (ISMP) reforçou a medida (Motta, 2017).

E é de olho no consumidor idoso e dos seus problemas de saúde que a indústria farmacêutica está atenta.

É sabido que os problemas de saúde tendem a aumentar com a idade. Nas mulheres, alvo fácil dos laboratórios, são medicamentos para TPM, anticoncepcionais, hormônios na menopausa e medicamentos para tratamentos da osteoporose. Portanto, em busca de qualidade de vida e de prevenção, existe também o forte mercado das vitaminas e suplementos.

É lógico que o maior número de idosos significa crescimento no consumo de medicamentos, já que doenças crônicas, como hipertensão e diabetes, tendem a surgir com o avançar da idade. As farmácias e drogarias são o principal canal de dispensação de medicamentos, logo, não há crise capaz de frear o crescimento do varejo farmacêutico, impulsionado por uma demanda natural.

O setor farmacêutico faturou entre abril de 2015 e início de 2016, 66 bilhões de reais, crescimento de $10 \%$ em relação ao período de um ano antes, segundo dados do IMS Health, divulgados pela Associação da Indústria Farmacêutica de Pesquisa (Interfarma), $\mathrm{o}$ ano de 2016 fechou na casa de 69 bilhões de reais.

Em 2017, somente no primeiro semestre, foram comercializados 1,8 bilhão de medicamentos. Em virtude do envelhecimento da população brasileira houve um significativo aumento da expectativa de vida, esses fatores resultaram no aumento da venda dos genéricos, de acordo com a Associação Brasileira das Indústrias de Medicamentos Genéricos (ProGenéricos), com base em dados do IMS Health.

Com isso, o IMS Health estima que o mercado farmacêutico brasileiro deverá alavancar em uma década, de $10^{\circ}$ para o $5^{\circ}$ lugar em faturamento mundial, ficando atrás apenas de grandes potências como Estados Unidos, China, Japão e Alemanha.

Na publicidade brasileira é comum a presença de idosos como avós no contexto das mensagens publicitárias, da velhinha engraçada que conversa com a neta em filme publicitário para vender chinelos, ou da senhora que exige determinada marca de presunto no supermercado, ou ainda de campanhas de vacinação da gripe, do Ministério da Saúde.

Os idosos dificilmente são alvo de campanhas publicitárias. Porém o idoso parece ser alvo fácil da publicidade quando o assunto é saúde. São comuns as promessas de medicamentos, terapias, tratamentos que visam protelar ou amenizar os efeitos da velhice. Nessa situação, depoimentos, testemunhais, presença de celebridades com discursos persuasivos ocupam espaço na mídia. Ainda é mais comum vermos os idosos na publicidade, junto à família. 


\section{O idoso na campanha do medicamento Benegrip Multi: o discurso da maturidade}

O presente trabalho utilizou a pesquisa exploratória em livros e artigos acadêmicos, assim como a pesquisa documental na mídia de massa: internet, TV, revista e mídia exterior, em busca de material verbal, visual e digital da campanha publicitária do medicamento Benegrip Multi, cuja protagonista foi a atriz brasileira Nicette Bruno, de oitenta e cinco anos de idade.

A campanha publicitária do medicamento Benegrip Multi, lançada em 2015 foi amplamente divulgada pela mídia de massa e utilizou a atriz Nicette Bruno, idosa, como protagonista, junto à sua família.

O medicamento Benegrip tem a função de combater os sintomas de gripes e resfriados. A empresa Hypermarcas lançou a campanha para promover a versão líquida de seu antigripal, o Benegrip Multi. O medicamento é indicado a crianças a partir de dois anos de idade e aos idosos ou adultos que possuem dificuldades para tomar comprimidos.

Por isso mesmo, a marca buscou transmitir sua mensagem publicitária por meio de uma celebridade idosa, sua filha, também atriz, e suas bisnetas, crianças.

Para representar o novo medicamento, a marca buscou a força de uma verdadeira família brasileira, conhecida do público."Nicette Bruno e Beth Goulart transmitem o sentimento de amor e conceito de família. Elas são queridas pelo público, demonstram o carinho e a atenção que possuem uma com a outra, além de serem muito respeitadas em seus trabalhos", explica Vesper Trabulsi, diretora de Marketing de Benegrip Multi.

A campanha contou com filme publicitário para TV, disponível no canal YouTube (https://www.youtube.com/watch?v=AEOf42KAEaI), spots em rádio, anúncios em revista e mobiliário urbano. A marca também investiu em mídia digital.

Nos anúncios de Benegrip Multi, percebe-se nas figuras 2, 3 e 4, mostradas anteriormente, a presença da família reunida, e a embalagem do medicamento em primeiro plano. A cores verde e laranja são destacadas, sendo que a bisneta de Nicette Bruno, também usa blusa laranja, a cor da marca. No relógio de rua, a atriz protagonista da campanha aparece apenas sozinha, até porque o formato menor do anúncio não permitiria a imagem da família. Mesmo assim a proposta da embalagem em primeiro plano se mantém, como nas demais peças publicitárias da campanha.

A palavra 'novo' aparece em destaque em todas as mídias, até porque trata-se de lançamento do produto Benegrip Multi, versão líquida.

No discurso persuasivo do filme publicitário, a atriz Nicette Bruno, aparece descontraída e animada. Brinca com a filha e as bisnetas enquanto apresenta o produto (Portal da Propaganda, 2016).

A atriz idosa aparece em todas as peças publicitárias da campanha, uma vez que é a protagonista e representa autoridade, sabedoria, 'prescrição'. É culturalmente comum no Brasil e em outros países a voz da experiência. Além da credibilidade, o discurso da maturidade, experiência, é relevante nas famílias brasileiras quando se 
trata de marcas de geração para geração, sobretudo quando se trata de medicamentos.

Portanto, na campanha de Benegrip Multi prevalece o discurso da maturidade, ou seja, a mãe, bisavó, madura e experiente 'indica' o medicamento à família e ao telespectador, provável consumidor.

Segundo a experiente atriz, em entrevista, "Sempre usei Benegrip e quando fui convidada pela marca para estar nesta campanha, aceitei na hora, pois acredito no medicamento". Para a atriz Beth Goulart é sempre um prazer trabalhar com a mãe. "É uma oportunidade maravilhosa lidar com a sabedoria de vida e profissional da minha mãe. Nosso entrosamento é ótimo na vida pessoal e no trabalho também. E isso é motivo de muita alegria pra mim", afirmou Beth. (Brandão, 2015).

Embora a campanha, em especial o filme publicitário, retrate cenas do cotidiano, trata-se de uma representação da atriz com sua filha e bisnetas. Assim como acontece em novelas. Não se sabe ao certo se as atrizes e as crianças consomem de fato o medicamento.

O fato é que a presença de celebridades na publicidade de medicamentos é algo antigo. Ronaldo, Pelé, Kaká, Maitê Proença, Giovanna Antonelli, Reynaldo Gianecchini, Hebe Camargo, Fausto Silva, Jô Soares, Marcius Melhem, são apenas alguns nomes de famosos brasileiros, que já fizeram parte do discurso persuasivo de celebridades em campanhas de medicamentos na mídia de massa.

Celebridade é uma pessoa amplamente reconhecida pela sociedade. A palavra deriva-se do latim celebritas, sendo também um adjetivo para célebre, alguém famoso. As agências de publicidade e as produtoras têm um cuidado todo especial ao selecionar a celebridade ao produto, não é diferente quando se trata de medicamento. Um dos aspectos que levam em consideração é que a celebridade tenha imagem e qualidades compatíveis com o produto e com a mensagem da campanha, assim como nas características que ligam o garoto-propaganda ao produto.

A grande discussão está no fato da celebridade deixar apenas de assumir um papel de interpretação e assumir o provável papel de agente da saúde, que aconselha, indica e prescreve o medicamento. É incontestável que grande parte da população brasileira atribui um poder de cura aos medicamentos, não importando como o mesmo é consumido (automedicação). Por isso, a questão da presença constante da celebridade em publicidade de medicamentos é polêmica. Artistas recebem cachês altos para representar e não necessariamente para testemunhar a verdade, fato que já torna o discurso suspeito. Mas a partir do testemunho, a credibilidade do discurso persuasivo passa a ter força e, o artista de televisão, com grande exposição na mídia, pode persuadir o consumidor, levando-o à compra, ao consumo, muitas vezes imediato. Tal fato impulsivo não deveria ocorrer no caso do medicamento. Por conta disso, o testemunhal de celebridades, na publicidade de medicamentos, que antes era comum passou a ter restrições e praticamente a inexistir no Brasil.

Desde 2009, segundo a ANVISA (Agência Nacional de Vigilância Sanitária) em Resolução estabelecida em 17 de dezembro de 2008, dentre outras exigências, o próprio ator que protagonizar o comercial do medicamento terá de verbalizar as advertências. 


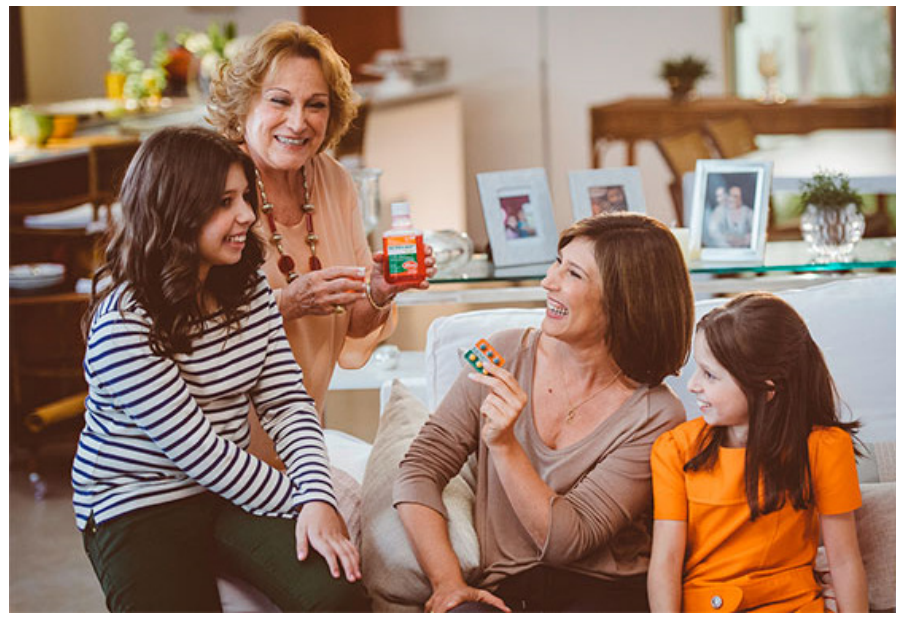

Figura 1 - Cena do filme publicitário Benegrip Multi. Reprodução.

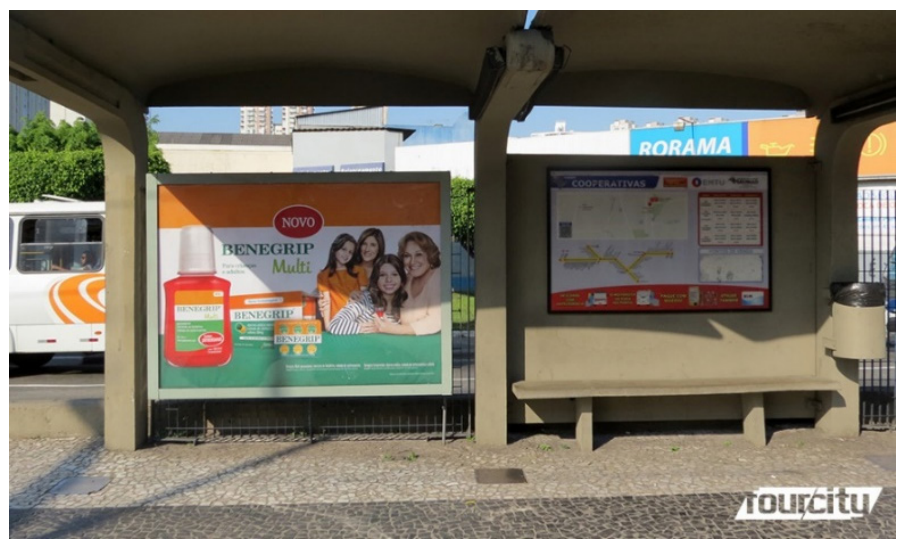

Figura 2 - Anúncio em mobiliário urbano. Reprodução.

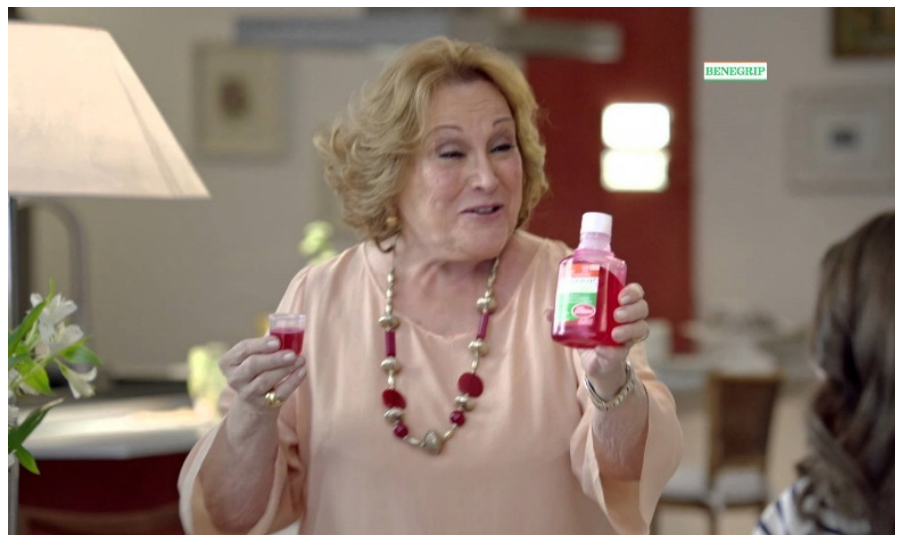

Figura 6 - Cena do filme publicitário Benegrip Multi. Reprodução. 


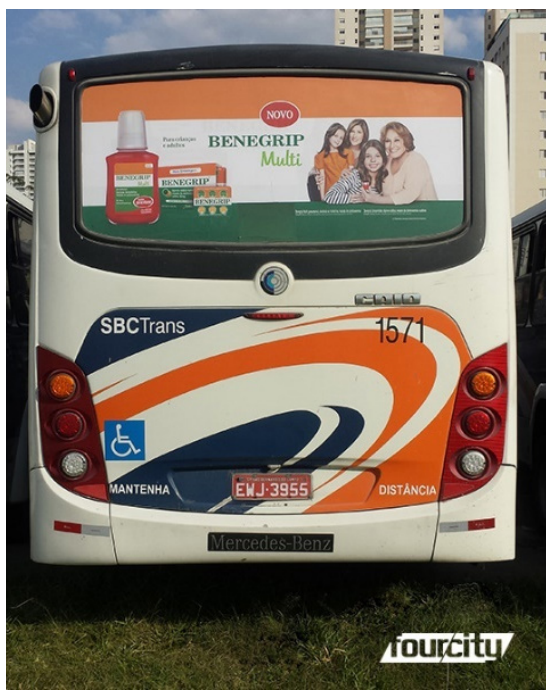

Figura 3 - Busdoor de Benegrip Multi. Reprodução.

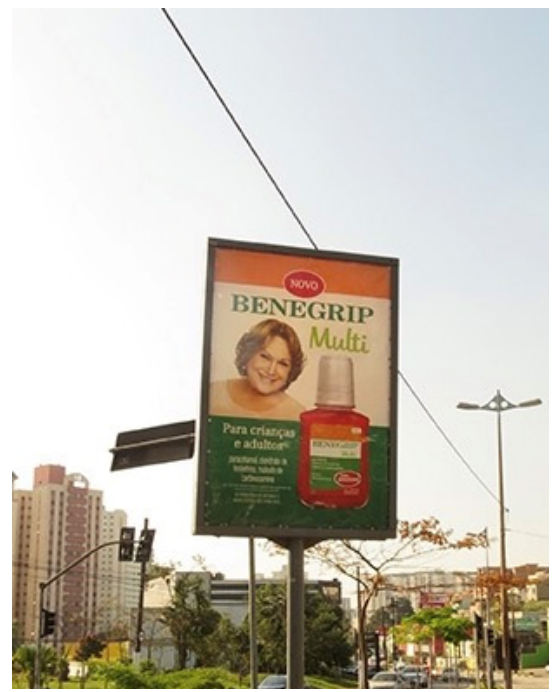

Figura 5 - Anúncio em mobiliário urbano. Reprodução.

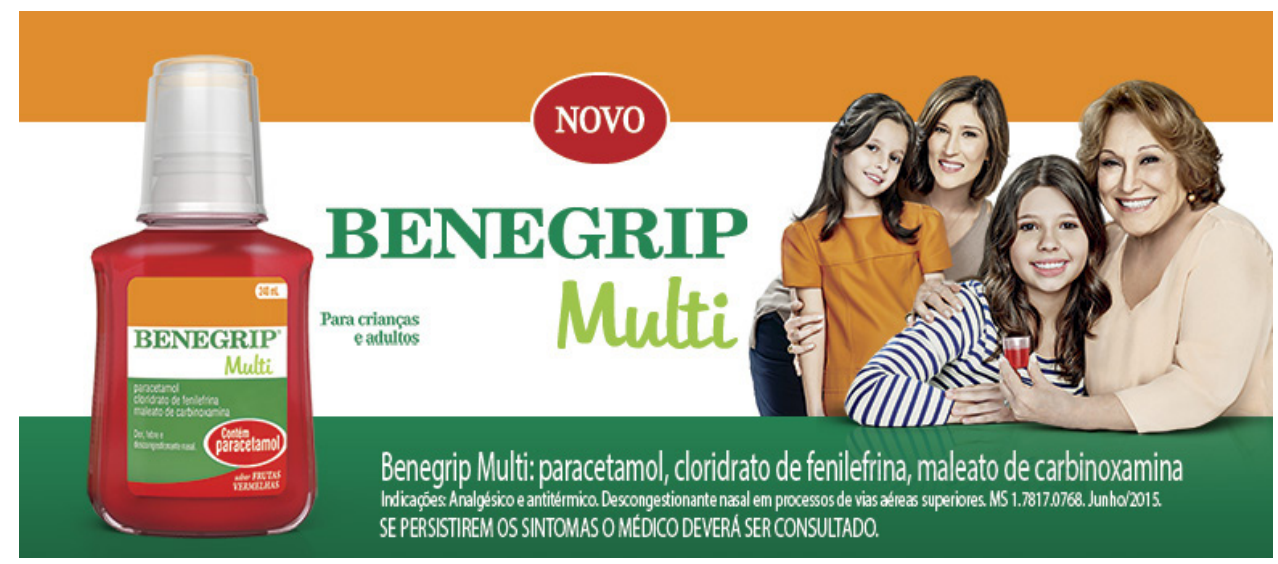

Figura 4 - Banner de internet. Reprodução. 
Na campanha de Benegrip Multi, Nicette Bruno não faz testemunhal, mas aparece segurando o produto, sugerindo que o usa e oferece à família e ao telespectador. Também ao dar entrevistas, afirma que utiliza o produto. Ou seja, as estratégias de marketing e da publicidade, tão presentes na indústria farmacêutica, de alguma maneira se mantêm, mesmo com Resoluções estabelecidas pela ANVISA, para controlar o consumo desenfreado de medicamentos no Brasil.

É o discurso da maturidade, onde os idosos estão inseridos, e que passa a fazer parte da publicidade brasileira, cada vez mais.

\section{Considerações finais e reflexão}

A longevidade ainda está um pouco distante da melhor idade. Com problemas de saúde, os idosos brasileiros passam por diversas dificuldades financeiras e sofrem com o descaso político e social no país.

Compreender o idoso, sob o ponto de vista apenas da idade, é não compreender a complexidade da situação, sem considerar aspectos históricos, culturais, psicológicos e sociais.

A indústria farmacêutica busca fidelizar o consumidor, seja pelo marketing, publicidade ou dependencia química, preferencialmente do "berço ao túmulo". Porém é nos idosos que se percebe o mal que o medicamento lhe fez durante uma vida.

Embora o mercado e a publicidade não tenham percebido a importância do discurso da maturidade, o mesmo existe e timidamente se apresenta em campanhas.

Atualmente no Brasil, a publicidade tem utilizado os idosos em campanhas na mídia de massa, inclusive para dialogar com os jovens. A indústria farmacêutica tem apresentado campanhas na mídia, utilizando celebridades idosas, como Nicette Bruno, famosa atriz de oitenta e cinco anos, protagonista da campanha Benegrip Multi.

A presença da atriz com a filha, netas e bisnetas, representando a união da familia, demonstra o quanto é importante o discurso da maturidade, sobretudo para o idoso, que vê no medicamento à busca pela cura, e na família, o caminho mais seguro para uma vida melhor.

\section{Referências}

Brandão, T (2017). Nicette Bruno e Beth Goulart estrelam campanha de Benegrip Multi. Recuperado en: 08 de setembro, 2017, de http://www.cidademarketing.com.br/2009/n/20625/ nicette-bruno-e-beth-goulart-estrelam-campanha-de-benegrip-multi.html.

Bueno, E. (2008). Vendendo Saúde - A história da propaganda de medicamentos no Brasil. Brasília: ANVISA.

Dor de cabeça e gripe não têm idade nem sexo (2014). Recuperado en: 12 de agosto, 2017, de http://www.nielsen.com/br/pt/insights/news/2014/Dor-de-cabeca-e-gripe-nao-tem-idadenem-sexo.html .

Família Nicette Bruno e Beth Goulart juntas em nova campanha (2016). Recuperado en: 11 
de novembro, 2017, de: http://www.portaldapropaganda.com.br/portal/component/content/ article/16-capa/46247-familia-nicette-bruno-e-beth-goulart-juntas-em-nova-campanha-deantigripal.

Farmácias de elite (2017). Recuperado en: 11 de setembro, 2017, de http://www.cff.org.br/ noticia.php?id=3879.

Idosos sentem falta de produtos - $67 \%$ dos brasileiros acima de 60 anos sentem falta de produtos e serviços específicos (2016). Recuperado en: 22 de agosto, 2017, de http://www. meioemensagem.com.br/home/marketing/2016/11/04/idosos-sentem-falta-de-produtosvoltados-para-a-terceira-idade.html.

Jesus, P. R. C. (2008). Slogans na propaganda de medicamentos. Um estudo transdisciplinar: Comunicação, Saúde e Semiótica. Tese de doutorado, PUC, São Paulo, SP, Brasil. Jesus, P. R. C (2014). Criação publicitária: conceitos, ideias e campanhas. São Paulo: Mackenzie.

Kedouk, M. (2016). Tarja Preta. São Paulo: Abril.

Lopes, R. (2000). Saúde na Velhice. São Paulo: EDUC.

Motta, T. Lista de medicamentos impróprios para idosos é atualizada nos EUA (2016).

Recuperado en: 11 de dezembro, 2017, de http://www.otempo.com.br/interessa/ sa\%C3\%BAde-e-ci\%C3\%AAncia/lista-de-medicamentos-impr\%C3\%B3prios-para-idosos\%C3\%A9-atualizada-nos-eua-1.1526669.

Nascimento, A. (2005). Isto é regulação? São Paulo: SOBRAVIME.

Número de idosos no Brasil cresceu 50\% em uma década, segundo IBGE (2017). Recuperado en: 28 de dezembro, 2017, de https://www.terra.com.br/noticias/dino/numero-de-idosos-nobrasil-cresceu-50-em-uma-decada-segundo-ibge,6427cac70c638ddd25efe9c43fb7d977r5spk pol.html.

O idoso, a publicidade e o direito do consumidor (2004). Recuperado en: 9 de setembro, 2017, de https://jus.com.br/artigos/4621/o-idoso-a-publicidade-e-o-direito-do-consumidor .

Perspectivas do Mercado Farmacêutico para 2018. (2017). Recuperado en: 5 de janeiro, 2018, de https://www.inovafarma.com.br/blog/perspectivas-do-mercado-farmaceutico-para-2018/.

Pessoa idosa - estatuto do idoso (2011). Recuperado en: 22 de setembro, 2017, de http://www. sdh.gov.br/assuntos/pessoa-idosa/programas/politica-nacional-do-idoso-e-o-estatuto-doidoso.

OMS divulga Relatório sobre envelhecimento, questiona estereótipos e aponta novos caminhos. Longevidade Adunicamp (2017). Recuperado en: 22 de agosto, 2017, de http:// longevidadeadunicamp.org.br/?p=1379 .

Solomon, M. R. (2002). O comportamento do consumidor. Porto Alegre: Bookman. Zanchi, Marco; Zugno, Paulo L. Sociologia da Saúde. Caxias do Sul: EDUCS, 2012. 


\section{The presence of the elderly in drug advertising in Brazil}

\section{Abstract}

The longevity grows in Brazil and in the world. Also grows the consumption of drugs. Therefore increasingly, the elderly are the target of the advertising of drugs in Brazil. In the advertising campaigns, the elderly generally appear with the family. This text, which is part of a broader research, aims to verify the elderly as current Brazilian consumer and their presence in the campaign of drugs in Brazil: Benegrip Multi.

\section{Keywords}

Advertising of drugs. Elderly. Brazil. 